\title{
Optimization of Extraction Techniques and RP-HPLC Analysis of Anti-Parkinson Drug Levodopa from Flowers of Vicia faba $L$.
}

\author{
İbrahim Bulduk \\ Department of Chemistry School of Health, Uşak University, Uşak 64200, Turkey
}

Received: 30 Dec 2019; accepted: 14 Feb 2020

\begin{abstract}
Vicia faba, also known as "bakla" in Turkey, is a species of Fabaceae family that is widely grown in Africa and Asia. It is rich in levodopa, a medicinal substance used to treat Parkinson's disease. Levodopa produced by chemical synthesis is expensive and causes various side effects. Therefore, it is recommended to use natural levodopa sources to prevent possible side effects. A Central Composite Design technique has been used in this study to optimize levodopa extraction from Vicia faba. First, a single factor analysis examined 3 variables such as extraction temperature, extraction time, and concentration of acetic acid. The purpose of this study was to assess the effects of variables chosen on levodopa's extraction performance. By using variance and regression analyses, a second-order regression equation was determined as a predicted model. The value of $R^{2}$ is 0.9882 , which shows that the equation fits well. The best conditions are as follows: a temperature of $59.85{ }^{\circ} \mathrm{C}$, an extraction time of $18.74 \mathrm{~min}$, and an acetic acid content of $0.28 \%$. Under optimum conditions, the maximum levodopa yield calculated from the predicted module was $4.53 \%$. Extraction efficiency was determined as $4.54 \%$ experimentally under optimum conditions. A good relationship has been found between the experimental result and the predicted value.
\end{abstract}

Keywords: Vicia faba, levodopa, extraction, HPLC

\section{Introduction}

Vicia faba, commonly known as "bakla" in Turkey, contains levodopa, a medicine used to treat Parkinson's disease (PD). It belongs to the family of the Fabaceae. Levodopa is found in a variety of natural products, such as Vicia faba and Mucuna pruriens $[1,2]$. Mucuna pruriens is considered to be the richest source of levodopa, since it may contain $9 \%$ of levodopa by weight [3]. Although Mucuna pruriens is very rich in levodopa, its use as a source of levodopa is very limited due to the limited geographical distribution in the tropics of Asia and Africa. Vicia faba is an alternative source of levodopa with around 4.5 million tonnes of annual production, mainly in Asia, Europe, and South America [4]. The wider geographical spread of Vicia Faba makes this plant a more interesting source of levodopa than Mucuna Pruriens. Figure 1 demonstrates the molecular structure of levodopa and Vicia faba.

Today, our society is interested in the use of environmentfriendly products in daily life. This situation causes people to choose more green and renewable sources and goods, including natural products, such as cosmetics and medicines. Levodopa is an amino acid used commonly in Parkinson's disease treatment [5]. Parkinson's disease develops in certain brain regions as a result of degeneration of dopaminergic neurons and mainly affects motor functions. Due to the lack of dopamine crossing the blood-brain barrier, Parkinson's patients are treated with levodopa, dopamine's starting material [6]. Levodopa has been recognized as the best cure for Parkinson's disease so far. Nonetheless, most side effects can be caused by levodopa administration, such as gastrointestinal discomfort or dyskinesia $[5,3]$.
Whatever levodopa's natural source, there is a need for more efficient, environmentally friendly and safe levodopa extraction methods. Although there are many extraction methods documented in the literature, these methods use concentrated acids or alcohols [1, 2-9]. The use of concentrated acids for the extraction of levodopa is effective, but restricted by the need for cost and intensive energy. In addition, in a strong acidic environment, the possible degradation of levodopa is a significant limitation for the future application of the production of levodopa. Alcohol usage such as methanol or ethanol may be an option, but the removal of alcohol in the final extracts may affect the concentration of levodopa [6]. A simple, sustainable, and robust method has been proposed in this study to extract levodopa from Vicia faba.

Different extraction parameters including the use of environmentally and human health-friendly solvents, extraction time, extraction temperature and other variables have been investigated to determine the best extraction conditions and reach maximum levodopa concentration.

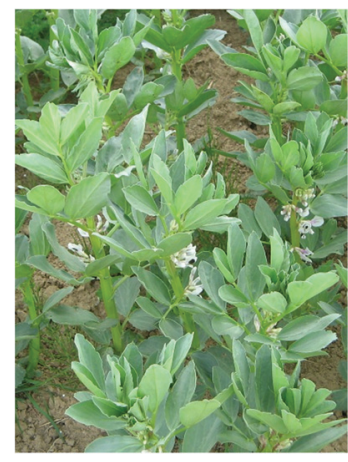<smiles>N[C@@H](Cc1ccc(O)c(O)c1)C(=O)O</smiles>

Figure 1. Vicia faba and molecular structure of levodopa purposes, provided the original author and source are credited, a link to the CC License is provided, and changes - if any - are indicated. 
Response surface methodology (RSM) is a methodology based on the suitability of experimental data to a polynomial equation, consisting of mathematical and statistical techniques. RSM looks for statistical explanation for the behavior of a data set. RSM searches for numerical reasons for the behavior of a data set. It can be applied very well in situations where multiple variables influence an answer. The method's aim is to optimize these variables simultaneously in order to achieve the highest organizational output [10]. The orthogonal experimental design and uniform design can only provide the best variable rate combination and cannot consider the most appropriate quality in the entire field. RSM can predict a multivariate quadratic equation's result (response). In the food [11-13] and pharmaceutical fields [14, 15], RSM was successfully applied. Two widely used approaches in RSM are Box-Behnken Design (BBD) $[10,16]$ and Central Composite Design (CCD) $[10,17]$. Through changing the number of central points, the CCD will achieve good features such as orthogonality, rotation, and flexibility.

The purpose of this study was the optimization of the conditions for levodopa extraction using RSM from Vicia faba. Five-level, three-factor CCD was utilized to analyze the impact on the extraction process of temperature, time, and concentration of acetic acid. The results of the study can be used as a theoretical guidance for the industrial production of levodopa from natural sources.

\section{Experimental}

Chemicals and Materials. Vicia faba used in this study was grown under the greenhouse conditions $\left(450 \mathrm{~m}^{2}\right)$ at the Faculty of Agriculture and Natural Sciences, Bilecik Şeyh Edebali University, in Turkey. Different organs of the plant were separated and dried in a dark room for 15 days. The dried material was ground to fine powder in a mill.

All chemicals used in the experimental studies were of analytical purity, and all solvents used for chromatographic purposes were of HPLC purity. All solvents and solutions $(0.45 \mu \mathrm{m})$ (Millipore, Bedford, MA, USA) were filtered using a membrane filter. Levodopa standard was purchased from Sigma Chemical Co.

Ultrasound-assisted extraction has been performed in a Wisebath brand ultrasonic water bath equipped with a $900-\mathrm{W}$ electric power and a frequency of $50 \mathrm{kHz}$, equipped with a digital timer and a temperature controller that controls both time and temperature. Ultrasound waves were generated at the base of the bath with a constant frequency $(50 \mathrm{kHz})$ and distributed to the water in the bath.

UAE Extraction Procedure. Exactly $500 \mathrm{mg}$ of the ground dried sample was weighed and transferred to a 100$\mathrm{mL}$ volumetric flask. A 40-mL extraction solvent was added thereto. For standard ultrasonic conditions, Erlenmeyer flasks were placed into the ultrasonic bath. The solvent level in the volumetric flask and the water level in the ultrasonic bath have remained the same. The time and temperature values of the ultrasonic bath were set and operated. After the extraction was completed, the mixture was filtered through a white band filter paper. The extracts were stored in a refrigerator at $4{ }^{\circ} \mathrm{C}$ until analysis.

Determination of Levodopa by HPLC. Quantitative analysis of levodopa was performed with Agilent 1260 model chromatographic system equipped with an auto sampler, quaternary pump, column compartment, and an UV-vis detector system. Separation was performed with an ACE 5 C18 column $(150 \mathrm{~mm} \times 4.6 \mathrm{~mm}, 5 \mu \mathrm{m})$. The mobile phase has been prepared by adding $20 \mathrm{ml}$ of methanol and $1 \mathrm{~mL}$ of glacial acetic acid to $979 \mathrm{~mL}$ of deionized water. The prepared mixture has been degassed. The flow rate of the mobile phase was performed at $1 \mathrm{~mL} / \mathrm{min}$ under isocratic conditions. The column thermostat temperature was kept constant at $30{ }^{\circ} \mathrm{C}$. Detection was performed at a $283-\mathrm{nm}$ wavelength. Injection volume of standard solutions and extracts was fixed at $20 \mu \mathrm{L}$. Analysis time was set at $10 \mathrm{~min}$. All HPLC analyses were performed in triplicate. The retention time of levodopa was $2.8 \mathrm{~min}$. The calibration curve is linear in the concentration range of 100-500 ppm $(y=12.275 x+85.77)\left(R^{2}=0.9993\right)$. The method was statistically validated for accuracy, precision, limit of detection (LOD), limit of quantification (LOQ), robustness, and recovery.

Single-Factor Experiments. Selection of extraction solvent: $500 \mathrm{mg}$ of the ground dried sample was accurately weighed into 5 different $100-\mathrm{mL}$ volumetric flasks. A $40-\mathrm{mL}$ solvent, namely, water, methanol, ethanol, acetic acid solution ( $1 \%$ in water), and ammonium hydroxide ( $1 \%$ in water), was added and extracted at a constant temperature and a constant ultrasound power in the ultrasonic bath for $30 \mathrm{~min}$.

In this study, single-factor analyses were performed to determine the central points and ranges of independent variables including $X_{1}$ (liquid to solid ratio), $X_{2}$ (extraction power), $X_{3}$ (extraction time), $X_{4}$ (extraction temperature), and $X_{5}$ (acetic acid concentration).

A single-factor experiment was used to investigate the effect of each factor on levodopa extraction. While one of the special factors changed, the other factors remained the same. The single factor contained liquid-to-solid ratio, extraction power, extraction time, extraction temperature, and acetic acid concentration. Five levels of each factor are shown in Table 1. As a result of the single factor experiments, 3 variables were selected for subsequent experiments, which significantly affected the extraction efficiency.

Response Surface Methodology. To find the optimum conditions for ultrasound-assisted extraction, the surface response approach was used. Three variables are selected based on the results of the single factor optimization. Each factor has been coded as $X_{1}-X_{3}$, and evaluated at 5 levels (Table 2). The 23 test runs were used at the center point, plus 6 replicates.

Table 2 displays the independent variables' coded and noncoded levels. The CCD shown in Table 3 was then used to examine the impact of the independent variables on the extraction of levodopa from Vicia faba. The yields of levodopa were obtained in response under different experimental conditions, presented in Table 4. Based on the following equation, each element is coded in 5 stages [18].

The Design-Expert (DE) design assumed that the main effects of variables have interactions and are based on a secondorder polynomial model [17-18]. The data obtained from the design was used to form a predicted model. The empirical

Table 1. Variable range of single factor experiments

\begin{tabular}{lccccc}
\hline Factor level & 1 & 2 & 3 & 4 & 5 \\
\hline Liquid-to-solid ratio $(\mathrm{mL} / \mathrm{g})$ & 20 & 30 & 40 & 50 & 60 \\
Acetic acid concentration \% & 0.1 & 0.2 & 0.3 & 0.4 & 0.5 \\
Extraction temperature $\left({ }^{\circ} \mathrm{C}\right)$ & 30 & 40 & 50 & 60 & 70 \\
Extraction power $(\mathrm{W})$ & 200 & 300 & 400 & 500 & 600 \\
Extraction time $(\mathrm{min})$ & 10 & 20 & 30 & 40 & 50 \\
\hline
\end{tabular}

Table 2. Specific variables and rates of Central Composite Design

\begin{tabular}{lccccccc}
\hline Independent & Units & Symbols & \multicolumn{5}{c}{ Code levels } \\
\cline { 3 - 8 } variables & & & -1.68 & -1 & 0 & +1 & +1.68 \\
\hline Ext. temp. & ${ }^{\circ} \mathrm{C}$ & $\left(X_{1}\right)$ & 26.36 & 40 & 60 & 80 & 93.64 \\
Ext. time & $\min$ & $\left(X_{2}\right)$ & 3.18 & 10 & 20 & 30 & 36.82 \\
Acetic acid conc. & $\%$ & $\left(X_{3}\right)$ & 0.05 & 0.15 & 0.30 & 0.45 & 0.55 \\
\hline
\end{tabular}


Table 3. Results obtained during the verification of the analytical process from testing various parameters

\begin{tabular}{llc}
\hline Parameters & & Results \\
\hline Specifity & Peak ratio of purity & 0.0015 \\
& Range of concentration $(\mu \mathrm{g} / \mathrm{mL})$ & $100-500$ \\
Linearity & Coefficient of correlation & 0.9993 \\
& Intercept & 85.770 \\
& Slope & 12.275 \\
LOD $(\mu \mathrm{g} / \mathrm{mL})$ & & 2.57 \\
LOQ $(\mu \mathrm{g} / \mathrm{mL})$ & & 7.75 \\
Retention time $(\mathrm{min})$ & 2.796 \\
\hline
\end{tabular}

Table 4. Encoded and uncoded statements and responses. Analysis of surface response and design of experimental values

\begin{tabular}{lcccc}
\hline \multicolumn{3}{c}{ Variables } & Response \\
\hline Run & $A$ : Temperature & $B$ : Time & $C$ : Acetic acid conc. & Levodopa \\
\hline & ${ }^{\circ} \mathrm{C}$ & min. & $\%$ & $\%$ \\
1 & $+1(80)$ & $-1(10)$ & $+1(0.45)$ & 3.50 \\
2 & $0(60)$ & $0(20)$ & $-1.68(0.05)$ & 3.97 \\
3 & $0(60)$ & $0(20)$ & $0(0.30)$ & 4.53 \\
4 & $+1(80)$ & $+1(30)$ & $+1(0.45)$ & 4.22 \\
5 & $+1(80)$ & $+1(30)$ & $-1(0.15)$ & 3.76 \\
6 & $-1(40)$ & $-1(10)$ & $+1(0.45)$ & 3.71 \\
7 & $-1(40)$ & $+1(30)$ & $-1(0.15)$ & 3.44 \\
8 & $0(60)$ & $0(20)$ & $0(0.30)$ & 4.46 \\
9 & $0(60)$ & $-1.68(3)$ & $0(0.30)$ & 3.90 \\
10 & $0(60)$ & $+1.68(37)$ & $0(0.30)$ & 3.77 \\
11 & $0(60)$ & $0(20)$ & $0(0.30)$ & 4.49 \\
12 & $+1.68(94)$ & $0(20)$ & $0(0.30)$ & 4.07 \\
13 & $0(60)$ & $0(20)$ & $0(0.30)$ & 4.54 \\
14 & $0(60)$ & $0(20)$ & $+1.68(0.55)$ & 3.81 \\
15 & $0(60)$ & $0(20)$ & $0(0.30)$ & 4.52 \\
16 & $+1(80)$ & $-1(10)$ & $-1(0.15)$ & 3.85 \\
17 & $0(60)$ & $0(20)$ & $0(0.30)$ & 4.51 \\
18 & $0(60)$ & $0(20)$ & $0(0.30)$ & 4.53 \\
19 & $-1(40)$ & $+1(30)$ & $+1(0.45)$ & 3.69 \\
20 & $0(60)$ & $0(20)$ & $0(0.30)$ & 4.56 \\
21 & $0(60)$ & $0(20)$ & $0(0.30)$ & 4.55 \\
22 & $-1.68(26)$ & $0(20)$ & $0(0.30)$ & 3.94 \\
23 & $-1(40)$ & $-1(10)$ & $-1(0.15)$ & 4.31 \\
\hline
\end{tabular}

quadratic polynomial model is shown in the equation below (Eq. (1)):

$$
Y=\beta_{0} \pm \sum_{j=1}^{k} \beta_{j} X_{j} \pm \sum_{j=1}^{k} \beta_{j j} X_{j}^{2} \pm \sum \sum_{i<j=2}^{k} \beta_{I i j J} X_{i I} X_{j J}
$$

In this equation, $Y$ is the response, $X_{i}$ and $X_{j}$ are variables ( $i$ and $j$ varying from 1 to $k$ ), $\beta_{0}$ is a fixed term, $\beta_{j}$ is the linear coefficient, $\beta_{i j}$ is the interaction coefficient, $\beta_{j j}$ is the secondorder coefficient, and $k$ is the number of independent parameters $(k=3$ in this study) [19-21].
Experimental data were analyzed by generalized least squares method and multiple regression analysis. Pareto variance analysis (ANOVA) was used to determine the statistical parameters. Minitab 16 software was used for surface response analysis. Results are expressed as mean \pm standard error; $P<0.05$ showed significant effects.

\section{Results}

Evaluation of Single Factors Affecting Levodopa Extraction

The Selection of Extraction Solvent. Selection of the extraction solvent was made by testing the extraction of levodopa with 5 different solvents (water, methanol, ethanol, 1\% acetic acid solution, and 1\% ammonium hydroxide solution). The results were given in Figure 2.

The highest levodopa yield was achieved using weakly acidic solvent ( $1 \%$ acetic acid solution) in this study for the selection of extraction solvent. The lowest levodopa yield $(86 \mathrm{mg} / \mathrm{mL})$ was obtained in the extraction with weak alkaline solvent ( $1 \%$ ammonium hydroxide solution). We determined the central points and the ranges of independent variables, namely, liquid-to-solid ratio $\left(X_{1}\right)$, extraction power $\left(X_{2}\right)$, extraction time $\left(X_{3}\right)$, extraction temperature $\left(X_{4}\right)$, and acetic acid concentration $\left(X_{5}\right)$ in this study.

Effects of Extraction Temperature. Extraction temperature is an important parameter affecting the extraction. The high extraction temperature can facilitate the lysis of the plant cells and facilitate the extraction of levodopa. The effects of temperature on levodopa extraction in the temperature range of 30-70 ${ }^{\circ} \mathrm{C}$ were examined, and the results are presented in Figure 3. The highest levodopa yield was obtained at $50{ }^{\circ} \mathrm{C}$ (200 mg/L). Levodopa yield increased from $154 \mathrm{mg} / \mathrm{L}$ to $200 \mathrm{mg} / \mathrm{L}$ in the temperature range of $30-50{ }^{\circ} \mathrm{C}$. Then, the efficiency of levodopa began to decrease. Meanwhile, levodopa yield was $183 \mathrm{mg} / \mathrm{L}$ at $60{ }^{\circ} \mathrm{C}$. It dropped to $168 \mathrm{mg} / \mathrm{L}$ at $70{ }^{\circ} \mathrm{C}$. The optimum temperature for levodopa extraction was considered to be $50{ }^{\circ} \mathrm{C}$.

Effects of Liquid-to-Solid Ratio. The effect of liquid-solid ratio in the range of $20-60 \mathrm{~mL} / 0.5 \mathrm{~g}$ on levodopa extraction was examined, and the results are presented in Figure 4. The extraction efficiency increased by increasing the liquid-solid ratio, in particular from $167 \mathrm{~mL} / 0.5 \mathrm{~g}$ to $222 \mathrm{~mL} / 0.5 \mathrm{~g}$, and then leveled. Thus, $40 \mathrm{~mL} / 0.5 \mathrm{~g}$ was selected for further experiments as the liquid-solid ratio.

Effects of Extraction Time. Extraction time is an important parameter affecting the extraction. Long extraction time may allow the extraction of levodopa from the plant matrix. In order to investigate the effect of extraction time on levodopa, extractions were performed in the range of 10-50 min. As

\section{Ledopa Extraction Efficiency}

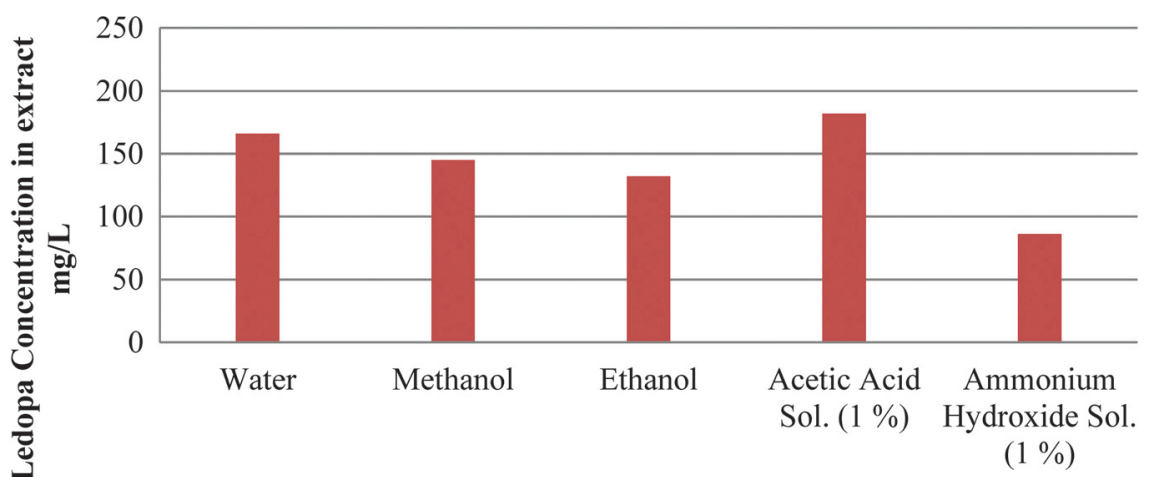

Extraction Solvent

Figure 2. Effects of different extraction solvents by ultrasound-assisted extraction (UAE) on the extraction yield 
Levodopa Extraction Efficiency

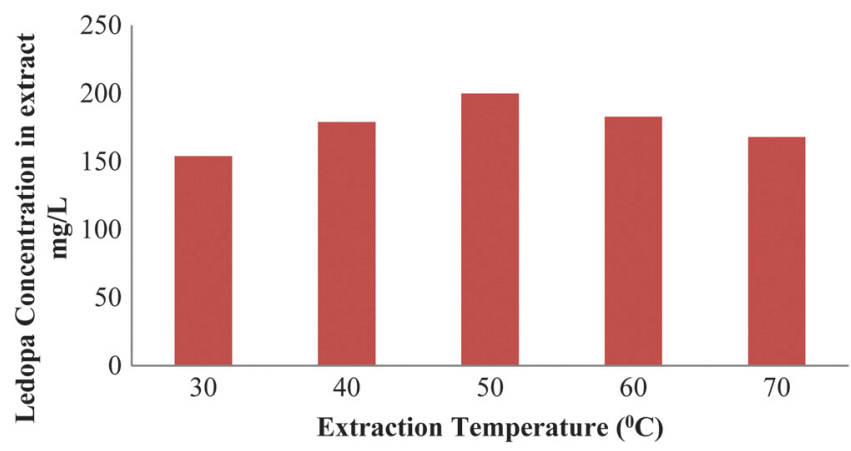

Figure 3. Effects of single-factor extraction temperature by ultrasound-assisted extraction (UAE) on the extraction yield

Levodopa Extraction Efficiency

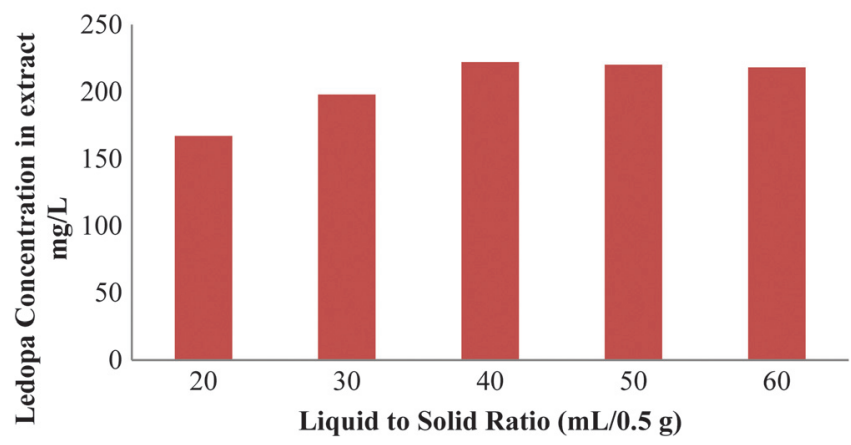

Figure 4. Effects of single-factor liquid-to-solid ratio by ultrasoundassisted extraction (UAE) on the extraction yield

shown in Figure 5, the yield increased significantly from 163 to $195 \mathrm{mg} / \mathrm{L}$ in the extraction time range of $10 \mathrm{~min}$ to $30 \mathrm{~min}$ and then leveled. Accordingly, an extraction time of $30 \mathrm{~min}$ was used for RSM tests.

Effects of Ultrasound Power. Ultrasound power is another important parameter that affects extraction. Higher ultrasound power results in more bubbles. Larger amplitude ultrasound waves can reach every point of the extraction solution. Therefore, the increase in ultrasound power can increase the extraction efficiency. However, an extremely high power can disrupt or disrupt the levodopa in the extracts, so optimum ultrasound power has been investigated. The effects of ultrasound power on levodopa extraction in the range of $200 \mathrm{~W}$ and $600 \mathrm{~W}$ were examined, and the results are presented in Figure 6. As previously noted, the extraction efficiency was slightly increased initially with the increase in ultrasound power, and when the

Levodopa Extraction Efficiency

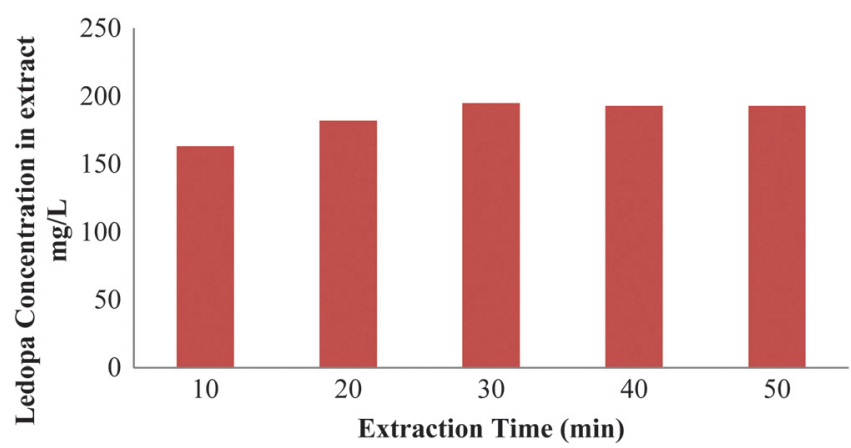

Figure 5. Effects of single-factor extraction time by ultrasoundassisted extraction (UAE) on extraction the yield
Levodopa Extraction Efficiency

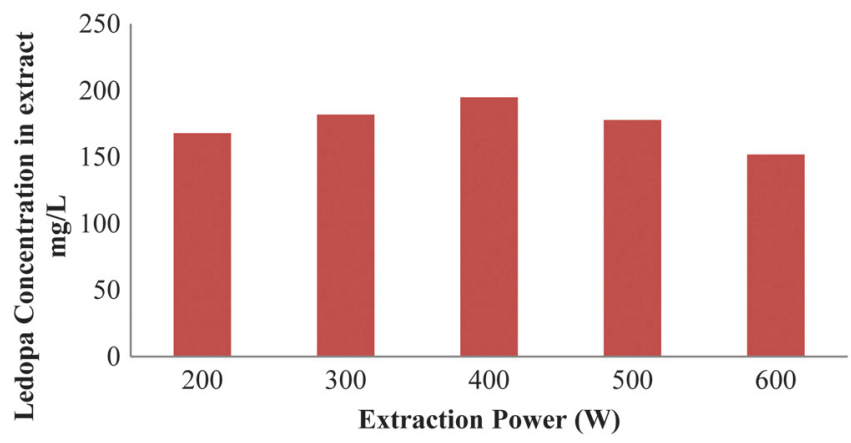

Figure 6. Effects of single-factor extraction power by ultrasoundassisted extraction (UAE) on the extraction yield

ultrasound power was $400 \mathrm{~W}$, the highest levodopa content of the extracts was recorded $(195 \mathrm{mg} / \mathrm{mL})$. However, there was no increase or decrease in efficiency when the ultrasound power increased from $400 \mathrm{~W}$ to $600 \mathrm{~W}$. Thus, $400 \mathrm{~W}$ was chosen as the preferred ultrasound power for the UAE process.

Effects of Acetic Acid Concentration. The acidic medium can improve the extraction of levodopa by breaking down the plant matrix. However, when concentrated acid is used, it may cause degradation of levodopa. To investigate the effect of acetic acid concentration on extraction yield, different concentrations of acetic acid solutions $(0.1 \%$ to $0.5 \%)$ were tested. Figure 7 shows the effect of the solvent on the levodopa extraction. When acetic acid concentration increased from $0.1 \%$ to $0.5 \%$, levodopa yield increased gradually and reached a peak of $200 \mathrm{mg} / \mathrm{L}$ at $0.3 \%$ concentration, but the acetic acid concentration increased from $0.3 \%$ to $0.5 \%$ levodopa yield did not change much. Accordingly, $0.3 \%$ acetic acid concentration was selected for RSM tests.

Validation of Analytical Method. The method has been validated according to International Council for Harmonization ( $\mathrm{ICH})$ guidelines in terms of precision, reliability, LOD, LOQ, robustness, and recovery, taking the recommendations of other applicable guidelines into account. The results obtained during the validation of the analytical method by testing different parameters were shown in Table 3.

Calibration Curves and Standard Solutions. At a concentration of $1000 \mu \mathrm{g} / \mathrm{mL}$, the standard stock solution of levodopa was prepared in water. The stock solution was diluted with water prior to calibration. The standard curve was prepared at 5 different concentration levels over a concentration range of $100-500 \mu \mathrm{g} / \mathrm{mL}$ levodopa. The linearity for levodopa was plotted using linear peak area versus concentration regression. The correlation coefficient

Levodopa Extraction Efficiency

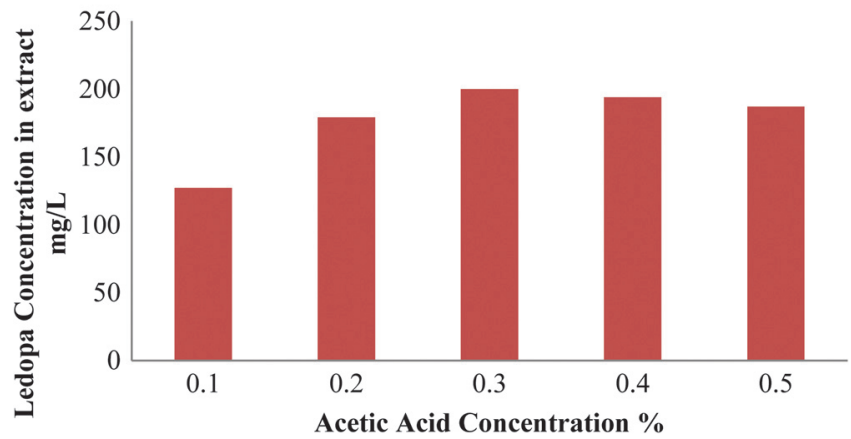

Figure 7. Effects of single-factor acetic acid concentration by ultrasound-assisted extraction (UAE) on the extraction yield 


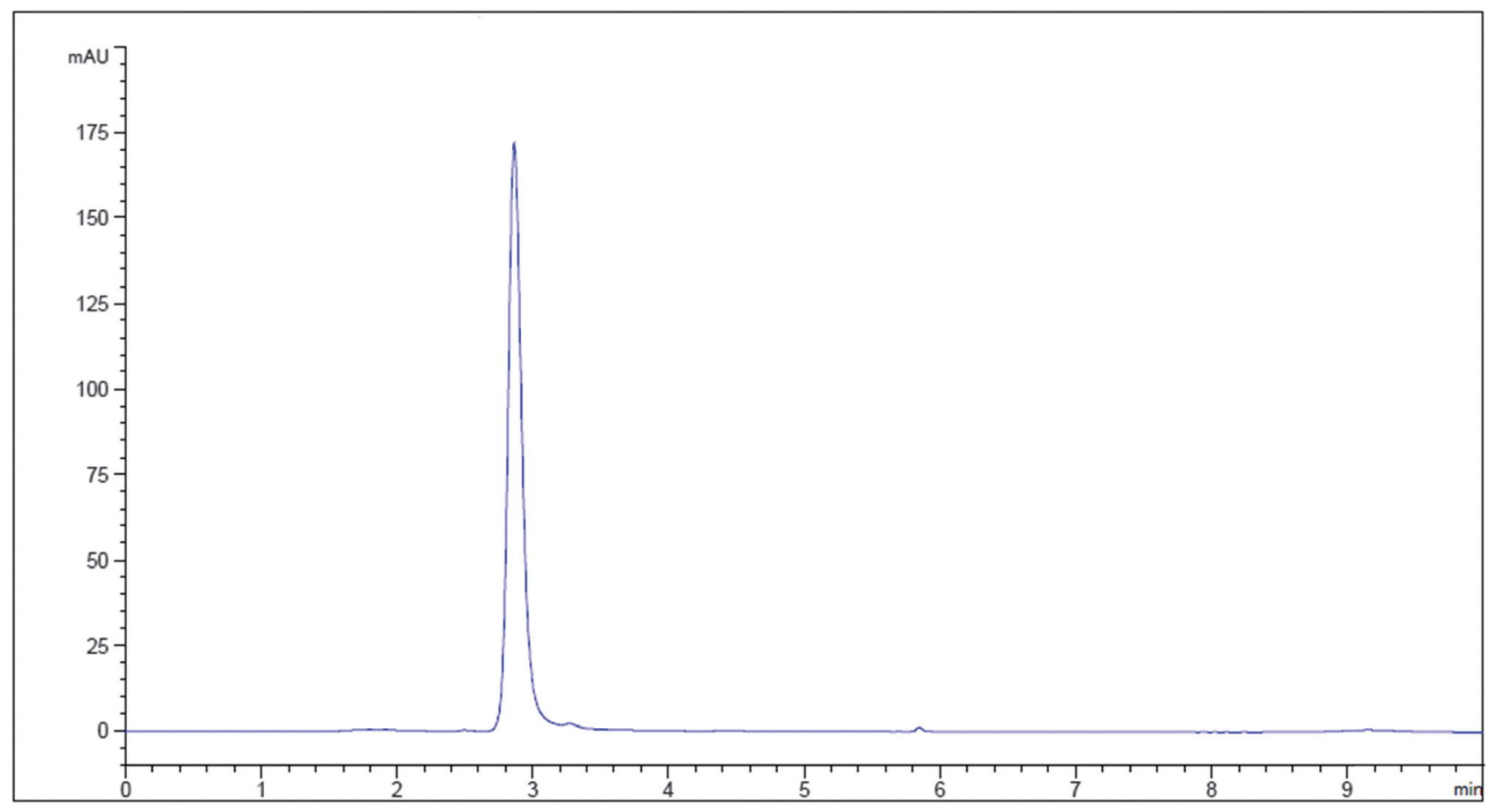

Figure 8. The HPLC chromatogram of the levodopa standard solution

$\left(R^{2}\right)$ was used to determine linearity. The LOD and LOQ for the tested compounds were determined by the signal-to-noise $(S / N)$ ratio. The results obtained from testing different parameters during the validation of the analytical method have been shown in Table 3. Figure 8 displays levodopa standard solution chromatogram. Figure 9 shows the chromatogram of Vicia faba flower extract.

Determination of Appropriate Model and Statistical Analysis. The RSM-based response values observed (levodopa yield) are shown in Table 4. Table 5 summarizes the experimental data ANOVA. The second order polynomial model for estimated levodopa yield is shown as coded values by using a multiple regression analysis on the experimental data.
ANOVA was used to check the importance of the model. $F$-value and $P$-value were checked for statistical significance of all model words. If the $F$-value is higher, and the Pvalue is lower, the related variables will be more important [22].

The 205.25 model $F$-value implies that the model is significant. $P$-values below 0.0500 imply that the terms of the model are significant. In this case, the elements of the layout are $A$, $B, C, A B, A C, B C, A^{2}, B^{2}$, and $C^{2}$. Values above 0.1000 mean that the terms of the model are not important. The $3.09 \mathrm{~F}$ value of Lack of Fit means that there is a $7.57 \%$ chance that such a high $F$-value of Lack of Fit could occur because of noise. Lack of fit is incorrect-we want to match the pattern.

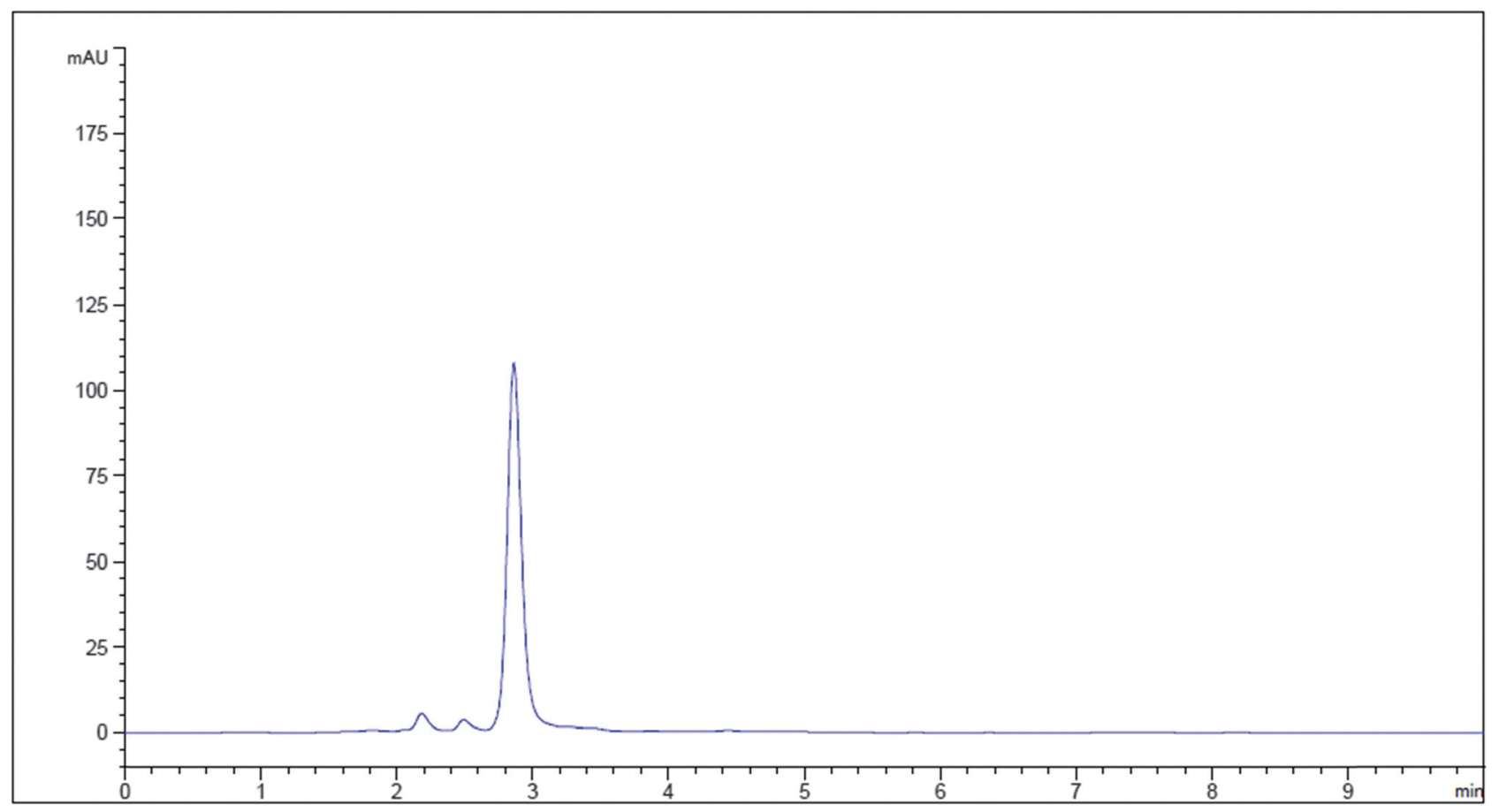

Figure 9. The HPLC chromatogram of the Vicia faba flowers extract 
Table 5. Estimated coefficient of regression (coded) and study of variance of the predicted model

\begin{tabular}{lccccc}
\hline Source & $\begin{array}{c}\text { Sum of } \\
\text { squares }\end{array}$ & $d f$ & $\begin{array}{c}\text { Mean } \\
\text { square }\end{array}$ & $F$-value & $p$-value \\
\hline Model & 3.21 & 9 & 0.3561 & 205.25 & $<0.0001$ \\
$A$ (Temperature) & 0.0116 & 1 & 0.0116 & 6.71 & 0.0224 \\
$B$ (Time) & 0.0168 & 1 & 0.0168 & 9.67 & 0.0083 \\
$C$ (Acetic acid conc.) & 0.0190 & 1 & 0.0190 & 10.94 & 0.0057 \\
$A B$ & 0.2888 & 1 & 0.2888 & 166.44 & $<0.0001$ \\
$A C$ & 0.0265 & 1 & 0.0265 & 15.24 & 0.0018 \\
$B C$ & 0.3445 & 1 & 0.3445 & 198.51 & $<0.0001$ \\
$A^{2}$ & 0.6074 & 1 & 0.6074 & 350.07 & $<0.0001$ \\
$B^{2}$ & 1.04 & 1 & 1.04 & 598.38 & $<0.0001$ \\
$C^{2}$ & 0.8863 & 1 & 0.8863 & 510.80 & $<0.0001$ \\
Residual & 0.0226 & 13 & 0.0017 & & \\
Lack of fit & 0.0149 & 5 & 0.0030 & 3.09 & 0.0757 \\
Pure error & 0.0077 & 8 & 0.0010 & & \\
Cor total & 3.23 & 22 & & & \\
\hline & & & & &
\end{tabular}

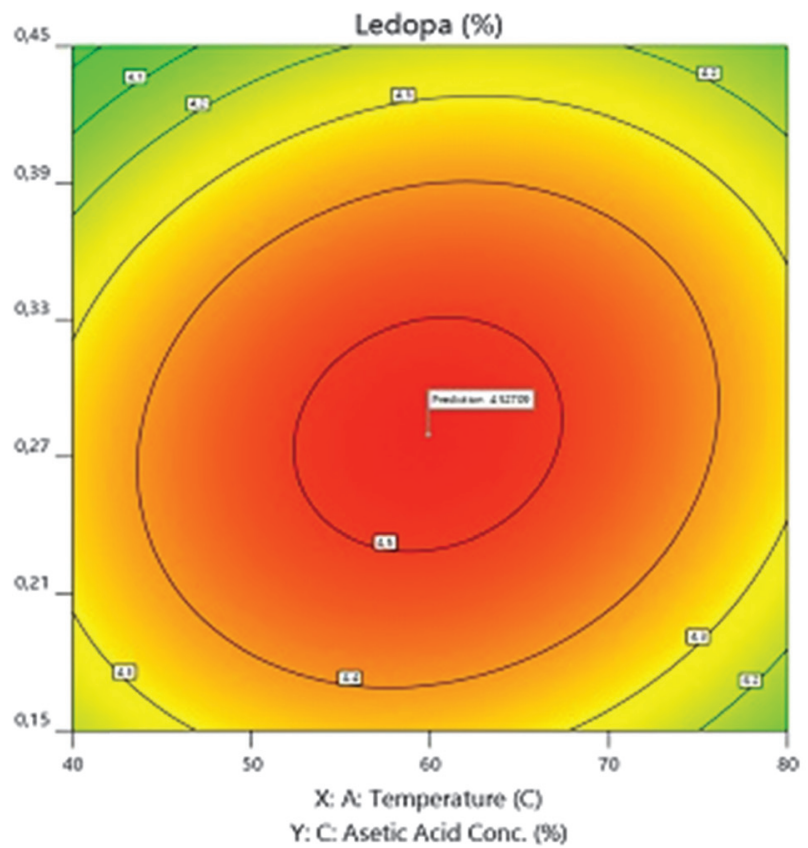

This relatively low chance $(<10 \%)$ is troubling. The final equation was given in terms of the coded factors The final equation was given below for coded factors.

Levodopa $\%=4.52+0.0292 A-0,0350 B-$ $0,0373 C+0.1900 A B+0.0575 A C+0.2075 B C-0.1955 A^{2}-$ $0.2556 B^{2}-0.2362 C^{2}$.

Figure 10 shows the contour plot for levodopa as a function of various extraction temperatures and solvent concentrations at constant extraction time $(18.748 \mathrm{~min})$ and liquid-solid ratio $(40 \mathrm{~mL} / 0.5 \mathrm{~g})$. It was found that the yield of levodopa increased rapidly with the extraction temperature rising from $50{ }^{\circ} \mathrm{C}$ to $60{ }^{\circ} \mathrm{C}$, but decreased rapidly with increasing extraction temperature above $60{ }^{\circ} \mathrm{C}$. In addition, levodopa yield increased with increasing acetic acid concentration from $0.15 \%$ to $0.30 \%$ and then decreased with increasing acetic acid concentration from $0.30 \%$ to $0.45 \%$.

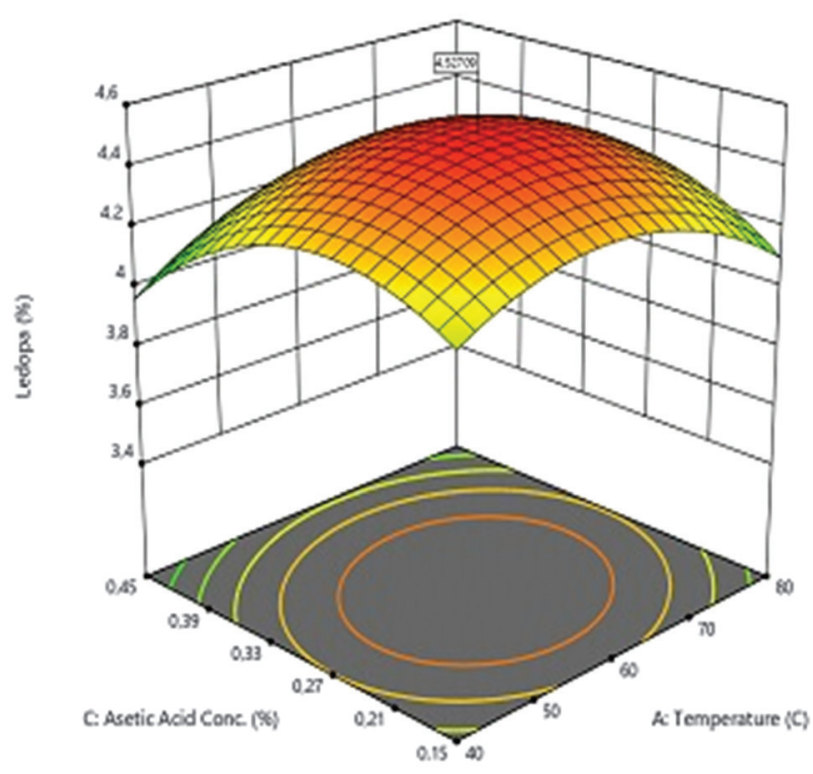

Figure 10. Contour plots and 3D surface graph show the effects of the ratio of the 2 single factors (extraction temperature versus solvent concentration)
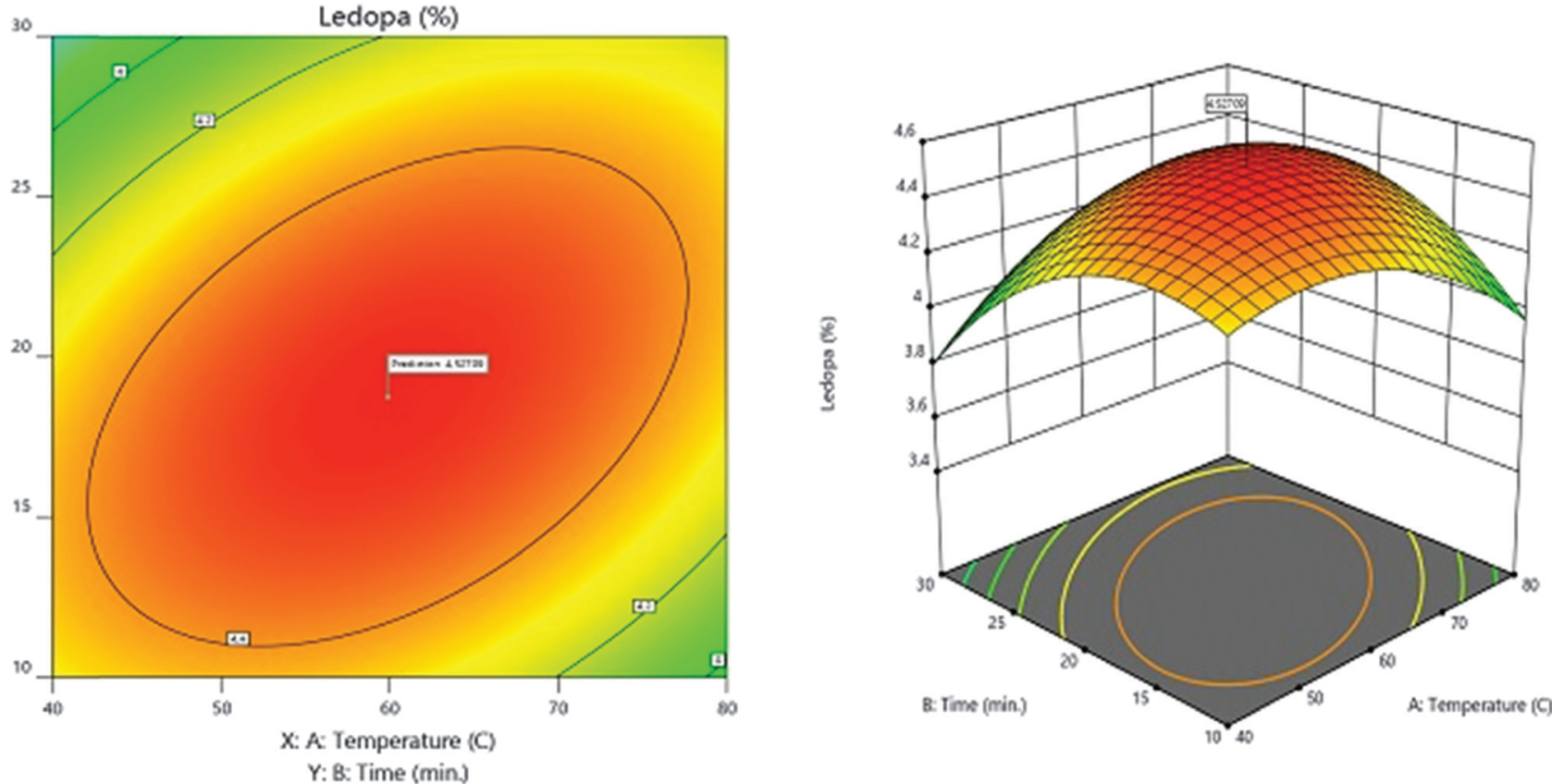

Figure 11. Contour plots and 3D surface graph show the effects of the ratio of the 2 single factors (extraction temperature versus extraction time) 

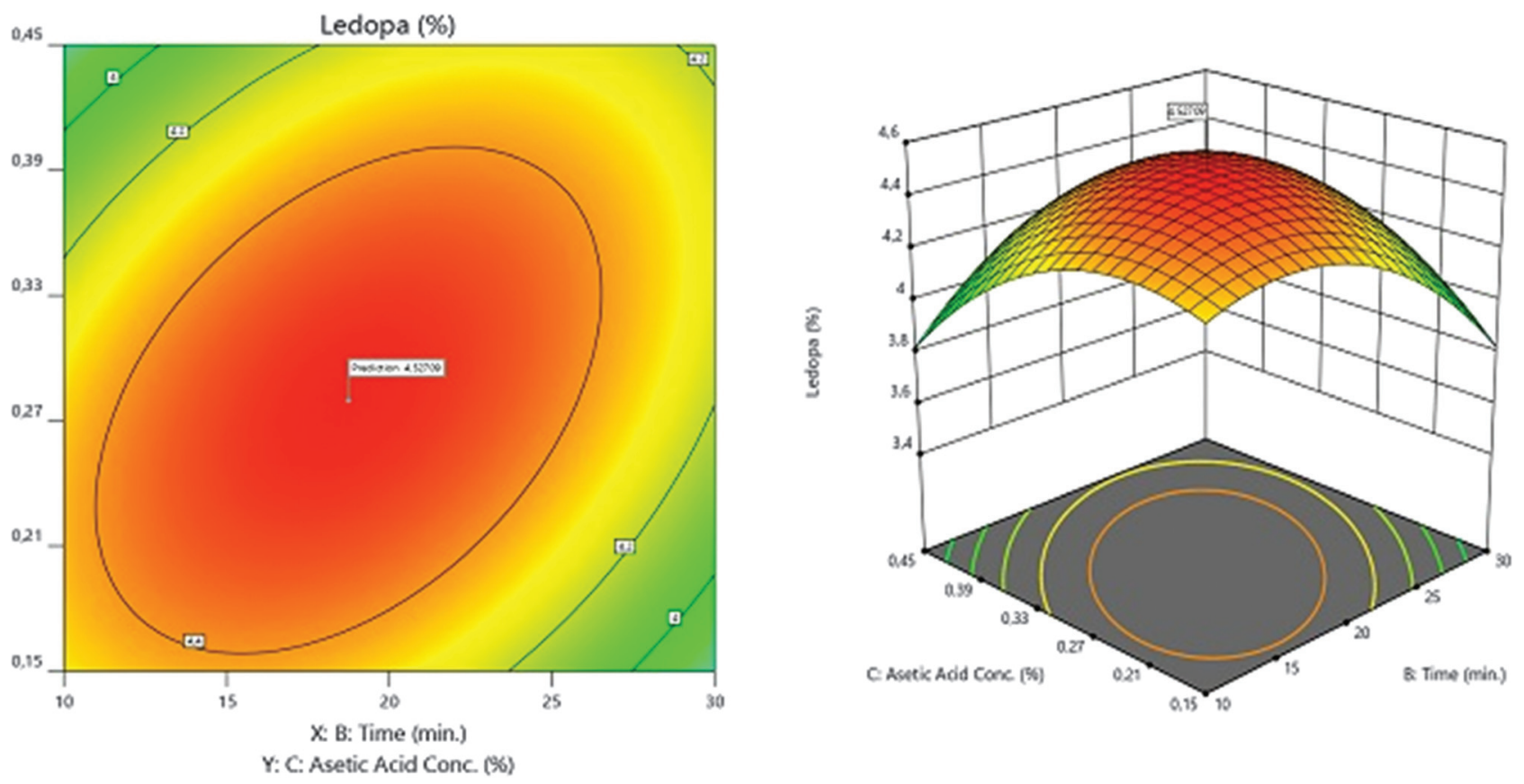

Figure 12. Contour plots and 3D surface graph show the effects of the ratio of the 2 single factors (extraction time versus solvent concentration)

Figure 11 shows the contour graph of levodopa as a function of various extraction temperatures and extraction times at a constant acetic acid concentration $(0.2798 \%)$ and liquidsolid ratio $(40 \mathrm{~mL} / 0.5 \mathrm{~g})$. The yield of levodopa rapidly increased from $50{ }^{\circ} \mathrm{C}$ to $60{ }^{\circ} \mathrm{C}$ at the extraction temperature and reached its maximum value. However, after $60{ }^{\circ} \mathrm{C}$, the yield did not increase and even decreased to some degree. In addition, the yield of levodopa increased rapidly by increasing from $10 \mathrm{~min}$ to $20 \mathrm{~min}$ of the extraction time, and then slightly decreased by increasing from $20 \mathrm{~min}$ to $30 \mathrm{~min}$ of the extraction time.

Figure 12 shows the contour plot for levodopa as a function of various extraction times and acetic acid concentration at a constant temperature $\left(59.886{ }^{\circ} \mathrm{C}\right)$ and liquid-solid ratio $(40 \mathrm{~mL} / 0.5 \mathrm{~g})$. The maximum levodopa yield was obtained when the extraction time was $18.74 \mathrm{~min}$ and the acetic acid concentration was $0.28 \%$.

Verifying the Predicted Values of the Model. The best conditions are the following: temperature of $59.85{ }^{\circ} \mathrm{C}$, extraction time of $18.74 \mathrm{~min}$, and the acetic acid content of $0.28 \%$. When optimal conditions were entered into the model equation, levodopa yield was calculated to be $4.53 \%$ from the model equation. Experiments for verification were performed under the most favorable conditions. The outcome revealed the experimental benefit $(4.54 \% ; n=6)$. The strong correlation between the expected and experimental value showed that the methodology of the response surface from Vicia faba was accurate and reliable in order to find the optimum conditions for ultrasonic extraction of levodopa. The optimum values of levodopa extraction from Vicia faba, the experimental value of levodopa obtained under these optimum conditions, and the predicted value of the model are given in Table 6.

Determination of Levodopa Content in Different Parts of Vicia faba. Levodopa contents of the flowers, leaf, and seed were analyzed by the verified and optimized HPLC method, and are presented in the Table 7.

\section{Discussion}

In the literature, several methods of extraction of levodopa from faba beans and velvet were identified. Mainly maceration
Table 6. Optimum conditions and predicted and experimental values

\begin{tabular}{lccccc}
\hline & Optimal condition & & \multicolumn{2}{c}{ Levodopa content $(\%)$} \\
\hline $\begin{array}{l}\text { Exrtraction } \\
\text { time }(\mathrm{min})\end{array}$ & $\begin{array}{c}\text { Extraction } \\
\text { temperature }\left({ }^{\circ} \mathrm{C}\right)\end{array}$ & $\begin{array}{c}\text { Acetic acid } \\
\text { conc. }(\%)\end{array}$ & & Experimental & Predicted \\
\hline 18.74 & 59.85 & 40.70 & & 4.54 & 4.53 \\
\hline
\end{tabular}

Table 7. Levodopa contents of the flowers, leaf, and seed of Vicia Faba L.

\begin{tabular}{lccc}
\hline Sample & Flowers & Leaf & Sead \\
\hline Levodopa sample $(\mathrm{mg} / \mathrm{g})$ & 45.40 & 31.30 & 4.24 \\
\hline
\end{tabular}

and Soxhlet extraction are conventional extraction methods from plant materials. These methods require long extraction times, the use of strong acids and toxic chemicals, or complex processes. Such complex processes make the levodopa extraction costly and demanding for energy, restricting its industrial application.

Polanowska sought to optimize the extraction of levodopa from the pods consumed as food. For this purpose, they investigated the variation of extraction parameters manually. No experimental optimization program was used in this study [23]. This study is the first report on a simple, rapid, robust, and green extraction method of levodopa from plant materials.

Ultrasound-assisted extraction has been shown to be a more efficient and environmentally friendly way of extracting natural antioxidants from plant materials due to its characteristics, namely, shorter extraction time and less use of organic solvents. The acoustic cavitation effect of ultrasound-assisted extraction improves the penetration of the solvent into the sample and increases the extraction output of the target components. Because the efficiency of an extraction process is typically determined by multiple factors, such as solvent concentration, solvent-to-solid ratio, extraction temperature, and time, the optimization of these parameters is very important to achieve high extraction yields [24].

In this study, the central composite design method was successfully applied to determine the optimum extraction conditions of levodopa from different organs of Vicia faba. 


\section{Conclusion}

The use of effective extraction methods can improve the use of natural products with high levels of bioactive compounds for behavioral chronic disease treatment such as Parkinson. Central Composite Design (CCD) was successfully used in this study to optimize the conditions of levodopa extraction from natural products. Independent variables (temperature of extraction, time of extraction, and concentration of acetic acid) have a major effect on the levodopa yield. To achieve the expected model, ANOVA and multiple regression analysis were used. The predicted optimum yield was calculated to be $4.53 \%$ from the model equation under optimum conditions $\left(59.85{ }^{\circ} \mathrm{C}\right.$ extraction temperature, $18.74 \mathrm{~min}$ extraction time, and $0.28 \%$ acetic acid concentration). It perfectly matched the result of repeated experimental yield $(4.54 \%, n=6)$ under the optimized conditions. The increased efficiency of levodopa provides cost savings and increases economic benefit. This study will help to standardize the procedures for the extraction of levodopa from natural products and to make a natural remedy against the symptoms of various diseases. Nonetheless, more research is needed for industrial applications to develop a mathematical model to control and estimate the parameters of optimization of the extraction process.

\section{References} 11078 .

1. Pulikkalpura, H.; Kurup, R.; Mathew, P. J.; Baby, S. Sci. Rep. 2015, 5, 2. Baranowska, I.; Płonka, J. Food Anal. Methods 2015, 8, 963.
3. Pugalenthi, M.; Vadivel, V. Food 2007, 1, 322.

4. FAO Food and Agriculture Organization of the United Nations. Agriculture Database. 2016. Available online: http://www.fao.org/faostat/en/ \#data/QC (accessed on 22 October 2018).

5. Jankovic, J. Neurology 2002, 58, 19.

6. Fahn, S. Ann. NY Acad. Sci. 2003, 991, 1.

7. Purves, R. W.; Zhang, H.; Khazaei, H.; Vandenberg, A. Int. J. Ion Mobil. Spectrom. 2017, 20, 125

8. Etemadi, F.; Hashemi, M.; Randhir, R. Z.; Vakili, O. Ebadi, A. Crop J. 2018, 6, 426.

9. Cardador, M. A.; Maya, O. K.; Ortiz, M. A.; Herrera, C. B. E.; Dávila,

O. G.; Múzquiz, M.; Martín, P. M.; Burbano, C.; Cuadrado, C.; Jiménez, M. C. J. Food Qual. 2012, 35, 419.

10. Bezerra, M. A.; Santelli, R. E.; Oliveira, E. P.; Villar, L. S.; Escaleira, L. A. Talanta 2008, 76, 965.

11. Chen, Y. Y.; Luo, H. Y.; Gao, A. P.; Zhu, M. Food Anal. Methods 2012, 5, 800.

12. Liu, X. L.; Mu, T. H.; Sun, H. N.; Zhang, M. Food Chem. 2013, 141, 3034.

13. Wu, S. H.; Gong, G. L.; Wang, Y. Y.; Li, F. Int. J. Biol. Macromol. 2013, 61, 63 .

14. Lan, M. B.; Guo, J.; Zhao, H. L.; Yuan, H. H. Asian J. Chem. 2012, $24,2290$. 1761 .

5. Hong, Y. K.; Liu, W. J.; Li, T.; She, S. Y. Carbohydr. Polym. 2013, 92,

16. Maran, J. P.; Manikandan, S.; Thirugnanasambandham, K.; Nivetha, C. V.; Dinesh, R. Carbohydr. Polym. 2013, 92, 604.

17. Zhu, T.; Heo, H. J.; Row, K. H. Chem. Res. Chin. Univ. 2012, 28, 620. 18. Maran, J. P.; Mekala, V.; Manikandan, S. Carbohydr. Polym. 2013, 92 , 2018.

19. Box, G. E. P.; Hunter, J. S. Ann. Math. Stat. 1957, 28, 195.

20. Samavati, V. Int. J. Biol. Macromol. 2013, 61, 142.

21. Maran, J. P.; Sivakumar, V.; Sridhar, R.; Immanuel, V. P. Ind. Crops Prod. 2013, 42, 159 .

22. Atkinson, A. C.; Donev, A. N. Clarendon Press. Britain 1992, 132.

23. Polanowska, K.; Lukasik, R. M.; Kuligowski, M.; Nowak, J. Molecules. 2019, 24, 2325.

24. Xu, D. P.; Zhou, Y.; Zheng, J.; Li, S.; Li, A. N.; Li, H. B. Molecules 2016, 21,18 . 